\title{
PERBANDINGAN PEMBENTUKAN GAP SENSITIVITAS PADA BANK SYARIAH MANDIRI (BSM) DAN BANK MEGA PERIODE 2011-20151)
}

\author{
Muhammad Wasiqul Firdaus Askarullah \\ Mahasiswa Program Studi S1 Ekonomi Islam-Fakultas Ekonomi dan Bisnis-Universitas Airlangga \\ Email : wasiqulfir@gmail.com \\ Achsania Hendratmi \\ Departemen Ekonomi Syariah-Fakultas Ekonomi dan Bisnis-Universitas Airlangga \\ Email : nia_rachmadi@yahoo.com
}

\begin{abstract}
:
Interest rate risk arise when there was a gap between assets and liabilities so the purpose of this study was to determine the position of the gap formed at Bank Syariah Mandiri (BSM) and Bank Mega and analyze the difference in the formation of gap based on the period of sensitivity $\leq 1$ month, > 1-3 months, and > 3-12 months.

This was a quantitative research with comparative study which uses sensitivity gap analysis to identify the position of the gap were formed and conduct the comparative analyzed with independent sample t-test and Mann-Whitney. The data being used was secondary data from Maturity Profile which contained in the Annual Financial Report of BSM and Bank Mega in the periods of 2011-2015.

The results showed that in BSM, cumulatively, the formation of the gap in the periods of 2011-2015 was negative gap. Likewise at Bank Mega, the cumulative gap formation in the periods of 2011-2015 was negative gap. From the results of independent sample t-test and Mann-Whitney known that the formation of the gap in BSM and Bank Mega for a period of sensitivity of $\leq 1$ month and $>1-3$ months showed a significant difference, while the period of sensitivity> 3-12 months there was no difference significant.

BSM suffered exposure to interest rate risk higher than the Bank Mega as the asset structure is dominated by Murabaha Financing (fixed rate) with long term (> 12 months) while liabilities dominated by Mudharabah Deposits (variable rate) with short-term (<12 months).
\end{abstract}

Keywords : Interest Rate Risk, Assets and Liability Management (ALMA), Gap Management

\section{PENDAHULUAN}

Sebagai lembaga intermediasi,

perbankan syariah akan selalu

berhadapan dengan berbagai jenis risiko

yang melekat pada kegiatan usahanya.

Risiko didefinisikan sebagai keseluruhan

hal yang dapat mengakibatkan kerugian

bagi perusahaan (Muslich, 2007:5).

Menurut Karim (2014:255), risiko dalam

konteks perbankan merupakan suatu

kejadian potensial, baik yang dapat

diperkirakan (anticipated) maupun yang tidak dapat diperkirakan (unanticipated)

yang ber-dampak negatif terhadap

pendapatan dan permodalan bank. Risiko-risiko tersebut tidak dapat dihindari, tetapi dapat dikelola dan dikendalikan.

Risiko utama yang dihadapi oleh bank syariah menurut Karim (2014:260) diklasifikasikan menjadi tiga jenis risiko, yaitu risiko pembiayaan, risiko pasar, serta risiko operasional. Risiko pasar merupakan risiko kerugian yang terjadi pada portofolio yang dimiliki oleh bank akibat adanya pergerakan variabel pasar (adverse movement) berupa suku bunga dan nilai tukar.

Jurnal ini merupkan bagian dari skripsi dari Muhammad Wasiqul Firdaus Askarullah, NIM : 041211431001 , yang diuji pada 21 Oktober 2016 
Risiko pasar yang diakibatkan pergerakan tingkat suku bunga terbukti berdampak masif terhadap perkembangan industri perbankan di Indonesia. Pengalaman krisis keuangan pada tahun 1998 memberi pelajaran berharga tentang begitu besarnya dampak risiko akibat pergerakan suku bunga tersebut. Pada tahun 1998, naiknya tingkat bunga yang relatif tinggi akibat krisis, menurut Laporan Bank Indonesia, menyebabkan kredit macet atau non-performing loan saat itu mencapai $70 \%$. Dalam periode Juli 1997 sampai dengan 13 Maret 1999, pemerintah telah menutup tidak kurang dari 55 bank disamping mengambil alih 11 bank (Bank Take Over / BTO) dan 9 bank lainnya dibantu melakukan rekapitalisasi (Alsa, 2004:2).

Secara teori, perbankan syariah di Indonesia memang tidak perlu waspada terhadap tingkat suku bunga karena tidak menggunakan instrumen-instrumen yang berbasis bunga. Bagaimanapun, dalam sistem perbankan ganda (dual banking system), secara tidak langsung tingkat bagi hasil perbankan syariah dipengaruhi oleh fluktuatifnya tingkat suku bunga karena beroperasi dalam sistem kevangan yang didominasi oleh perbankan konvensional (Chapra, dkk., 2002:59). Hal ini disebabkan pasar yang dijangkau oleh perbankan syariah tidak hanya untuk nasabah-nasabah yang loyal penuh terhadap prinsip Syariah (Karim, 2014:272). Bila terjadi tingkat bagi hasil pada produk simpanan perbankan syariah lebih kecil dari tingkat bunga maka nasabah dapat berpindah ke perbankan konvensional. Sebaliknya pada sisi pembiayaan, jika tingkat bagi hasil yang dikenakan lebih besar daripada tingkat bunga, maka nasabah dapat beralih ke perbankan konvensional.

Di antara sekian banyak piranti manajemen risiko, langkah antisipasi yang bisa dilakukan berkaitan dengan risiko tingkat suku bunga adalah manajemen gap. Gap merupakan perbedaan atau selisih antara aset yang sensitif terhadap suku bunga (Rate Sensitive Asset/RSA) dengan liabilitas yang sensitif terhadap suku bunga (Rate Sensitive Liability/RSL). Sedangkan manajemen gap bertujuan mempersempit lebarnya kesenjangan antara Rate Sensitive Asset (RSA) dengan Rate Sensitive Liability (RSL) tersebut (Riyadi, 2006:133).

Posisi gap yang terbentuk akibat mismatch pada RSA dan RSL dapat memberikan informasi tentang potensi risiko perbankan syariah seiring dengan adanya perubahan tingkat suku bunga sehingga pengelolaan gap yang tepat akan berpengaruh terhadap kinerja perbankan syariah.

Berdasarkan uraian diatas, peneliti tertarik untuk meneliti lebih lanjut mengenai manajemen gap pada perbankan syariah dilihat dari posisi pembentukannya. Adapun Bank Syariah yang digunakan sebagai sampel penelitian adalah Bank Syariah Mandiri (BSM). Hingga Desember 2015, BSM merupakan Bank Syariah dengan pangsa pasar dan aset terbesar dalam industri perbankan 
syariah di Indonesia. Aset BSM tercatat telah mencapai sebesar Rp. 70,37 triliun, pembiayaan yang disalurkan sebesar Rp. 51,09 triliun, sedangkan dana pihak ketiga (DPK) yang berhasil dihimpun dari masyarakat mencapai sebesar Rp. 62,11 triliun.

BSM juga merupakan Bank Syariah pertama yang masuk dalam kategori Bank BUKU III, yaitu Bank dengan modal inti antara Rp. 5 - 30 triliun. Dalam www.syariahmandiri.com yang diakses pada tanggal 29 Agustus 2016, BSM mendapat tambahan modal inti sebesar Rp. 500 miliar dari Bank Mandiri selaku pemilik saham mayoritas pada 25 November 2015 sehingga jumlah modal inti BSM menjadi Rp. 5,4 triliun dan total ekuitas menjadi Rp. 5,62 triliun.

Disisi lain, penelitian ini juga akan memperbandingkan pembentukan gap pada perbankan syariah dengan perbankan konvensional untuk melihat perbedaan pembentukan gap sehingga manajemen perbankan syariah dapat menggunakan hasil penelitian sebagai dasar pengambilan keputusan strategisnya serta menjadi referensi tambahan mengenai manajemen gap perbankan syariah dalam perspektif yang lebih luas, yaitu industri perbankan. Sampel Bank Konvensional yang digunakan dalam penelitian ini yaitu Bank Mega. Seperti halnya BSM, Bank Mega juga merupakan Bank yang termasuk kategori BUKU III. Per Desember 2015, jumlah modal inti Bank Mega sebesar Rp. 10,28 triliun dan total ekuitas Rp. 11,52 triliun. Untuk aset Bank
Mega tercatat sebesar Rp. Rp. 68,23 triliun dan dana pihak ketiga (DPK) sebesar Rp. 49,74 triliun.

Persamaan ukuran sampel tersebut menjadi penting sebagai tolak ukur yang seimbang untuk melihat perbandingan pembentukan gap. Adapun periode gap dibagi dalam beberapa periode sensi-tivitas berdasarkan ketentuan dari The Banking of International Settlement (BIS) yang tertuang dalam Basel Capital Accord II tahun 1996 yaitu jangka waktu kurang dari satu bulan ( $\leq 1$ bulan), lebih dari satu sampai dengan tiga bulan (> 1-3 bulan), dan lebih dari tiga bulan sampai dengan satu tahun (> 3-12 bulan).

\section{Perumusan Masalah}

1. Bagaimana posisi gap yang terbentuk di Bank Syariah Mandiri (BSM) dan Bank Mega pada periode sensitivitas $\leq 1$ bulan, > 1-3 bulan, dan > 3-12 bulan selama tahun $2011-2015$ ?

2. Apakah terdapat perbedaan pembentukan gap di Bank Syariah Mandiri (BSM) dan Bank Mega pada periode sensitivitas $\leq 1$ bulan, > 1-3 bulan, dan > 3-12 bulan selama tahun $2011-2015$ ?

\section{Tujuan Penelitian}

1. Untuk menganalisis posisi gap yang terbentuk pada Bank Syariah Mandiri (BSM) dan Bank Mega periode 20112015.

2. Untuk menguji apakah terdapat perbedaan pembentukan gap pada Bank Syariah Mandiri (BSM) dan Bank Mega periode 2011-2015. 


\section{LANDASAN TEORI}

\section{Risiko Tingkat Suku Bunga}

Menurut Karim (2014:272), meskipun perbankan syariah tidak menetapkan tingkat bunga, baik dari sisi pendanaan, maupun sisi pembiayaan, tetapi per-bankan syariah tidak akan dapat terlepas dari risiko tingkat suku bunga. Hal ini disebabkan pasar yang dijangkau oleh perbankan syariah tidak hanya untuk nasabah-nasabah yang loyal penuh ter-hadap syariah. Bila terjadi bagi hasil pendanaan syariah lebih kecil dari tingkat suku bunga, nasabah dapat pindah ke bank konvensional, sebaliknya pada sisi financing, bila margin yang dikenakan lebih besar dari tingkat suku bunga maka nasabah dapat beralih ke bank konven-sional.

\section{Manajemen Risiko}

Kountur (2006) dalam Loristiana (2009:30) mendefinisikan manajemen risiko sebagai cara-cara yang digunakan manajemen untuk menangani berbagai permasalahan yang disebabkan oleh adanya risiko. Berkaitan dengan risiko tingkat suku bunga yang dihadapi oleh perbankan syariah, salah satu tindakan preventif yang dapat dilakukan adalah dengan melaksanakan Asset Liability Management (ALMA).

Menurut Riyadi (2006:21), ALMA pada dasarnya adalah suatu proses planning, organizing, actuating, dan controlling untuk mendapatkan penetapan kebijaksanaan di bidang pengelolaan permodalan (equity), pemupukan dana (funding), dan penggunaan dana (asset) yang satu sama lain saling terkait (koordinasi) dalam mencapai tingkat laba yang optimal dengan tingkat risiko yang telah diperhitungkan. Muhamad (2015:210) menyebutkan komponen-komponen yang dipergunakan dalam menyusun kebijakan tersebut yaitu foreign exchange manage-ment, net open position (posisi devisa neto), manajemen gap, risk analysis, dan pengendalian cost of funds.

\section{Manajemen Gap}

Riyadi (2006:133) menjelaskan, gap merupakan perbedaan atau selisih antara aset yang sensitif terhadap suku bunga (Rate Sensitive Asset / RSA) dengan liabilitas yang sensitif terhadap suku bunga (Rate Sensitive Liability / RSL). Sedangkan manajemen gap bertujuan mempersempit lebarnya kesenjangan antara Rate Sensitive Asset (RSA) dengan Rate Sensitive Liability (RSL) tersebut. Secara definisi, manajemen gap merupakan pengaturan gap yang disebabkan tingkat (degree of) sensitivitas dari masing - masing pos aset maupun masing - masing pos liabilitas yang berbeda-beda.

Menurut tingkat kepekaannya, aset/liabilitas dibagi menjadi dua jenis, yaitu rate sensitive assets-liablities dan fixed rate assets-liablities (Antonio, 2001:180). Aset yang digolongkan sebagai rate sensitive assets (RSA) adalah semua aset, termasuk aset dengan bunga tetap (fixed rate), yang mempunyai jatuh tempo kurang dari 1 (satu) tahun (jangka pendek) atau aset dengan bunga 
mengambang (floating rate) yang harus diperbaharui setiap 1 (satu) bulan, 3 (tiga) bulan, 6 (enam) bulan, dan maksimal 1 (satu) tahun. Liabilitas yang digolongkan rate sensitive liablities (RSL) adalah semua liabilitas, termasuk liabilitas dengan bunga tetap (fixed rate liabilities), yang mempunyai jatun tempo tidak lebih dari 1 (satu) tahun, atau pinjaman dengan bunga mengambang yang harus diperbaharui setiap 1 (satu) bulan, 3 (tiga) bulan, atau 6 (enam) bulan, atau tidak lebih dari 1 (satu) tahun. Formulasi umum tentang manajemen gap yaitu :

Posisi Gap = RSA - RSL (Riyadi, 2006)

Rasio Gap $=\frac{\text { RSA-RSL }}{\text { Total Aset }}$ (Hanafi, 2009)

\section{Posisi Gap}

Menurut Antonio (2001:179), potensi risiko tingkat suku bunga muncul manakala terjadi gap antara aset dan liabilitas, dimana komposisi RSA tidak sesuai atau mismatch dengan komposisi RSL. Dengan mengacu pada mismatch tersebut, maka dapat terbentuk tiga jenis posisi gap yaitu (Riyadi, 2006:136-137) :

a. Zero Gap, apabila RSA = RSL

Zero gap menandakan rendahnya variabel risiko dalam menunjang pendapatan karena kuantitas aset sensitif terhadap suku bunga sama dengan kuantitas kewajiban sensitif terhadap suku bunga

b. Positive Gap, apabila RSA > RSL

Pada posisi gap positif, aset sensitif terhadap suku bunga lebih besar daripada kewajiban sensitif terhadap suku bunga (RSA>RSL). Nilai ini mengindikasikan bahwa sebagian RSA dibiayai dengan dana yang tidak sensitif.

c. Positive Gap, apabila RSA > RSL

Pada posisi gap negatif, Rate Sensitive Asset lebih kecil daripada Rate Sensitive Liabilities (RSA<RSL).

Hubungan antara posisi gap, perubahan tingkat suku bunga dan pengaruhnya terhadap pendapatan terdapat pada Tabel 2.1 berikut (Riyadi, 2006: 138) :

Tabel 2.1

Hubungan Gap, Tingkat Suku Bunga, dan Pendapatan

\begin{tabular}{|c|c|c|}
\hline Posisi gap & $\begin{array}{l}\text { Tingkat } \\
\text { bunga }\end{array}$ & Pendapatan \\
\hline \multirow{2}{*}{ Zero Gap } & Naik & Tetap \\
\hline & Turun & Tetap \\
\hline \multirow{2}{*}{$\begin{array}{c}\text { Positive } \\
\text { Gap }\end{array}$} & Naik & Naik \\
\hline & Turun & Turun \\
\hline \multirow{2}{*}{$\begin{array}{c}\text { Negative } \\
\text { Gap }\end{array}$} & Naik & Turun \\
\hline & Turun & Naik \\
\hline Sumber: & $\begin{array}{l}\text { Riyadi, Slame } \\
\text { Assets } \\
\text { Management } \\
\text { Lembaga P } \\
\text { Ekonomi Unive }\end{array}$ & $\begin{array}{l}\text { 2006. Banking } \\
\text { Liability } \\
\text { Jakarta: } \\
\text { erbit Fakultas } \\
\text { tas Indonesia }\end{array}$ \\
\hline
\end{tabular}

\section{Hipotesis}

$\mathrm{H}_{1}$ : Terdapat perbedaan signifikan pembentukan gap antara Bank Syariah Mandiri (BSM) dan Bank Mega pada periode sensitivitas $\leq 1$ bulan.

$\mathrm{H}_{2}$ : Terdapat perbedaan signifikan pembentukan gap antara Bank Syariah Mandiri (BSM) dan Bank Mega pada periode sensitivitas $>$ 1-3 bulan.

$\mathrm{H}_{3}$ : Terdapat perbedaan signifikan pembentukan gap antara Bank Syariah Mandiri (BSM) dan Bank Mega pada periode sensitivitas $>$ 3-12 bulan.

\section{Metode Analisis}


Metode analisis yang digunakan dalam penelitian ini adalah analisis gap sensitivitas serta analisis perbandingan dengan uji beda. Analisis gap sensitivitas digunakan untuk mengukur aset dan kewajiban yang sensitif terhadap perubahan risiko pasar sehingga diketahui posisi gap yang terbentuk berdasarkan periode sensitivitas. Uji beda untuk menguji apakah pembentukan gap berdasarkan periode sensitivitas memiliki perbedaan. Model analisis dalam penelitian ini adalah sebagai berikut :

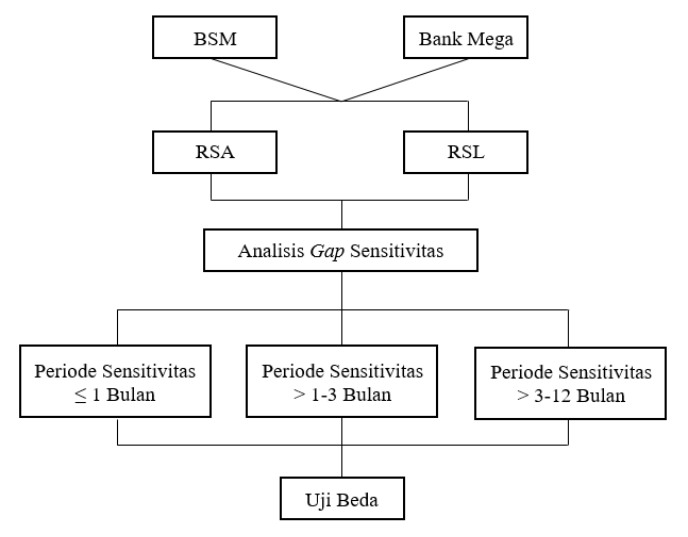

Gambar 2.1

Model Analisis

\section{METODE PENELITIAN}

Penelitian yang dilakukan penulis menggunakan pendekatan kuantitatif, yaitu berupa analisis gap sensitivitas dan uji beda untuk melihat perbandingan hasil pembentukan gap pada perbankan syariah dan perbankan konvensional yang bersumber dari laporan keuangan perusahaan. Uji beda merupakan salah satu teknik statistik parametrik yang digunakan untuk menguji hipotesa komparatif (uji perbedaan).

\section{Identifikasi Variabel}

Variabel dalam penelitian ini mengacu pada model analisis yang digunakan oleh peneliti dalam menjawab permasalahan. Model analisis yang memuat beberapa teknik analisis memberikan perbedaan variabel yang dipakai dalam masing-masing teknik. Adapun variabel yang dipakai dalam penelitian ini adalah sebagai berikut :

1. Analisis Gap Sensitivitas

a. RSA = Rate Sensitive Assets

b. $\mathrm{RSL}=$ Rate Sensitive Liabilities

2. Analisis Perbandingan (Uji Beda)

a. Rasio Gap

\section{Definisi Operasional}

Untuk memberikan keterangan lebih jelas terhadap variabel-variabel yang digunakan di dalam penelitian ini, maka variabel-variabel tersebut didefinisikan :

1. Rate Sensitive Assets (RSA)

Aset yang digolongkan sebagai rate sensitive assets (RSA) adalah semua aset, termasuk aset dengan bunga tetap (fixed rate), yang mempunyai jatuh tempo kurang dari 1 (satu) tahun (jangka pendek) atau aset dengan bunga mengambang (floating rate) yang harus diperbaharui setiap 1 (satu) bulan, 3 (tiga) bulan, 6 (enam) bulan, dan maksimal 1 (satu) tahun.

2. Rate Sensitive Liabilities (RSL)

Liabilitas yang digolongkan rate sensitive liablities (RSL) adalah semua liabilitas, termasuk liabilitas dengan bunga tetap (fixed rate liabilities), yang mempunyai jatuh tempo tidak lebih dari 1 (satu) tahun, atau 
pinjaman dengan bunga mengambang yang harus diperbaharui setiap 1 (satu) bulan, 3 (tiga) bulan, atau 6 (enam) bulan, atau tidak lebih dari 1 (satu) tahun.

3. Rasio Gap

Rasio yang digunakan untuk mengukur gap akibat perubahan fluktuatif dari tingkat suku bunga. Rasio ini menunjukkan sensitivitas terhadap tingkat suku bunga. Adapun rumus perhitungannya sebagai berikut :

$$
\text { Rasio Gap }=\frac{\text { RSA }- \text { RSL }}{\text { Total Aset }}
$$

\section{Jenis dan Sumber Data}

Penelitian ini menggunakan data sekunder yang diperoleh dari laporan keuangan tahunan Bank Syariah Mandiri (BSM) dan Bank Mega pada periode 2011 - 2015. Data sekunder yang dibutuhkan dalam penelitian ini yaitu Maturity Profile atau Analisa Jatuh Tempo yang berisi informasi mengenai jumlah aset dan liabilitas pada setiap periode sensitivitas.

\section{Populasi dan Sampel Penelitian}

Populasi dalam penelitian ini adalah seluruh Bank Umum Syariah (BUS) dan Bank Umum Konvensional (BUK) di Indonesia. Sampel yang diambil yaitu Bank Syariah Mandiri (BSM) sebagai Bank Umum Syariah (BUS) dan Bank Mega sebagai Bank Umum Konvensional (BUK).

\section{Teknik Analisis}

Dalam penelitian ini, teknik analisis yang digunakan ialah analisis gap sensitivitas dan uji beda.

\section{Analisis Gap Sensitivitas}

Langkah dalam analisis ini adalah sebagai berikut :

1. Menyusun Mismatch Rate Sensitivity Pengelompokkan repricing/maturity schedule yaitu penyusunan aset dan kewajiban berdasarkan penetapan tingkat bunga baru atau tingkat bagi hasil dan margin, dan berdasarkan jatuh tempo, serta pengelompokkan aset dan kewajiban berdasarkan tingkat kesensitifannya. Mengikuti pendekatan Ali (2004), penyusunan kerangka gap untuk suku bunga dilakukan dengan mengelompokkan asset-liabilities dalam empat kelompok, yaitu Rate Sensitive Asset (RSA), Fixed and Non Rate Sensitive Asset (NRSA), Rate Sensitive Liabilities (RSL) dan Fixed Rate dan Non Rate Sensitive Liabilities (NRSL).

Tabel 3.1

Matriks Analisis Gap Sensitivitas

\begin{tabular}{|l|l|l|l|}
\hline \multicolumn{1}{|c|}{ RSA } & $\begin{array}{c}\text { Fixed Rate } \\
\text { \& NRSA }\end{array}$ & \multicolumn{1}{c|}{ RSL } & $\begin{array}{c}\text { Fixed Rate, } \\
\text { NRSL \& ekuitas }\end{array}$ \\
\hline 1. Penempatan & 1. Kas & 1. Simpanan & 1. Pinjaman \\
2. Efek-efek & 2. Investasi & 2. Pinjaman & jangka \\
$\begin{array}{l}\text { yang } \\
\text { yariabel dan } \\
\text { traded }\end{array}$ & $\begin{array}{l}\text { 3. Securities } \\
\text { asset } \\
\text { lainnya }\end{array}$ & $\begin{array}{l}\text { 3. Kewajiban } \\
\text { lainnya }\end{array}$ & 2. Eknjang \\
3. Obligasi \\
$\begin{array}{l}\text { pemerintah } \\
\text { 4. Kredit }\end{array}$ & & & \\
\hline
\end{tabular}

Sumber : Ali, M. 2004. Asset-Liability Management: Menyiasati Risiko Pasar dan Risiko Operasional Dalam Perbankan. Jakarta : Elex Media Komputindo

2. Risk Analysis

Analisis terhadap gap yang terjadi akibat perubahan suku bunga:

$$
\begin{gathered}
\text { Posisi Gap }=\text { RSA }- \text { RSL, dan } \\
\text { Rasio Gap }=\frac{\text { RSA }- \text { RSL }}{\text { Total Aset }}
\end{gathered}
$$

\section{Uji Beda}


Langkah - langkahnya adalah sebagai berikut:

1. Menghitung Rasio Gap untuk masingmasing bank sampel selama periode penelitian.

2. Melakukan uji normalitas (Kolmogrovsmirnov). Data akan berdistribusi normal saat nilai sig $>0,05$, sedangkan saat nilai sig $<0,05$ maka data berdistribusi tidak normal.

3. Apabila data penelitian berdistribusi normal dan memenuhi asumsi parametrik, maka diuji menggunakan alat uji † (Independent Sample t-test). Sedangkan apabila data penelitian berdistribusi tidak normal maka alat uji yang digunakan adalah uji statistik nonparametrik Mann-Whitney (MannWhitney Test). Berikut langkahlangkahnya:

1. Menentukan hipotesis operasional

a. $H_{0}: \mu_{1}=\mu_{2}$, tidak ada perbedaan yang signifikan pembentukan gap antara Bank Syariah Mandiri dan Bank Mega

b. $H_{A}: \mu_{1} \neq \mu_{2}$, ada perbedaan yang signifikan pembentukan gap antara Bank Syariah Mandiri dan Bank Mega

2. Menentukan level of significant (a) sebesar $a=5 \%$

3. Menentukan kriteria pengujian

a. $\mathrm{H}_{0}$ diterima dan $\mathrm{H}_{\mathrm{A}}$ ditolak, apabila Sig. > 0,05 ini menunjukkan bahwa tidak ada perbedaan yang signifikan pembentukan gap antara
Bank Syariah Mandiri (BSM) dan Bank Mega. (uji t)

b. $H_{0}$ diterima dan $H_{A}$ ditolak, apabila Asymp.sig > 0,05 ini menunjukkan bahwa tidak ada perbedaan yang signifikan pembentukan gap antara Bank Syariah Mandiri (BSM) dan Bank Mega. (uji Mann Whitney)

\section{HASIL DAN PEMBAHASAN}

\section{Analisis Gap Sensitivitas}

Dari analisis gap sensitivitas yang sudah dilakukan kemudian dapat disimpulkan pembentukan posisi gap oleh BSM selama tahun 2011-2015 adalah negatif gap seperti yang ditunjukkan oleh Gambar 4.1.

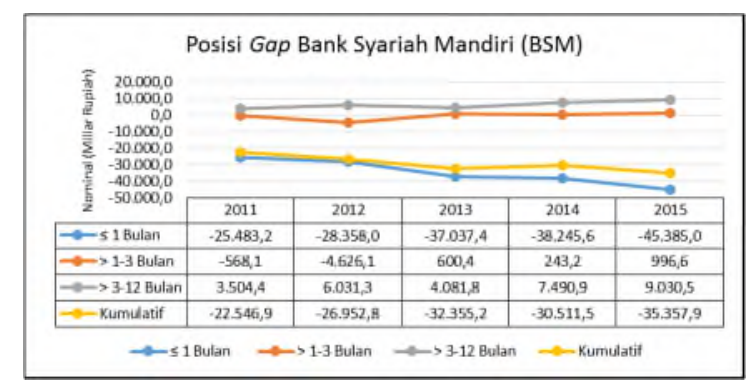

Sumber : Hasil Analisis Gap Sensitivitas Bank Syariah Mandiri (BSM)

\section{Gambar 4.1.}

Posisi Gap Bank Syariah Mandiri (BSM) Tahun 2011-2015

Pada periode sensitivitas $\leq 1$ bulan posisi gap yang terbentuk adalah negatif gap, pada periode sensitivitas > 1-3 bulan menunjukkan hasil yang fluktuatif. Pada tahun 2011 dan 2012 posisi gap yang dihasilkan adalah negatif sedangkan tahun 2013-2015 BSM mampu menghasilkan posisi gap yang positif. Secara kumulatif, periode sensitivitas ini menghasilkan posisi gap negatif, dan 
pada periode sensitivitas $>3-12$ bulan menunjukkan hasil positif gap.

Posisi gap negatif secara kumulatif menunjukkan bahwa selama 5 tahun ini jumlah aset BSM yang sensitif terhadap perubahan tingkat suku bunga benchmark lebih kecil dari pada jumlah liabilitas yang sensitif terhadap perubahan suku bunga. Maka, posisi negatif gap ini akan menyebabkan turunnya pendapatan BSM jika terjadi peningkatan suku bunga sementara ketika suku bunga turun terjadi peningkatan pada pendapatan bank.

Hasil analisis gap sensitivitas pada Bank Mega menunjukkan bahwa pembentukan posisi gap Bank Mega selama tahun 2011-2015 adalah negatif gap seperti yang ditunjukkan oleh Gambar 4.2.

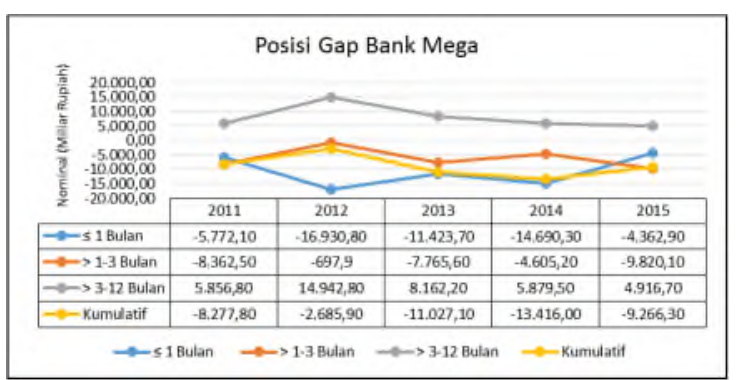

Sumber : Hasil Analisis Gap Sensitivitas Bank Mega

Gambar 4.2.

Posisi Gap Bank Mega Tahun 201 1-2015

Pada periode sensitivitas $\leq 1$ bulan posisi gap yang terbentuk adalah negatif gap, pada periode sensitivitas > 1-3 bulan menunjukkan hasil negatif gap, dan pada periode sensitivitas $>$ 3-12 bulan menunjukkan hasil positif gap.

Posisi gap negatif secara kumulatif menunjukkan bahwa selama 5 tahun ini jumlah aset Bank Mega yang sensitif terhadap perubahan tingkat suku bunga benchmark lebih kecil dari pada jumlah liabilitas yang sensitif terhadap perubahan suku bunga. Maka, posisi negatif gap ini akan menyebabkan turunnya pendapatan Bank Mega jika terjadi peningkatan suku bunga sementara ketika suku bunga turun terjadi peningkatan pada pendapatan bank.

\section{Analisis Hasil Penelitian dan Pengujian Hipotesis \\ Uji Normalitas}

Hasil uji normalitas ditunjukkan oleh Tabel 4.3. sebagai berikut :

Tabel 4.3.

Hasil Uji Normalitas

\begin{tabular}{|l|r|r|r|}
\hline & \multicolumn{3}{|c|}{ Shapiro-Wilk } \\
\cline { 2 - 4 } & Statistic & df & \multicolumn{1}{|c|}{ Sig. } \\
\hline $\begin{array}{l}\text { RASIO GAP SENSITIVITAS } \leq \\
\text { 1 BULAN }\end{array}$ & .876 & 10 & .119 \\
$\begin{array}{l}\text { RASIO GAP SENSITIVITAS } \\
\text { 1-3 BULAN }\end{array}$ & .874 & 10 & .113 \\
$\begin{array}{l}\text { RASIO GAP SENSITIVITAS } \\
\text { 3-12 BULAN }\end{array}$ & .785 & 10 & .010 \\
\hline
\end{tabular}

a. Lilliefors Significance Correction

Tabel 4.3. diatas menunjukkan Rasio Gap periode sensitivitas $\leq 1$ bulan dan > 1-3 bulan terdistribusi normal karena memiliki nilai signifikansi ditas 0,05 sehingga pengujian menggunakan uji $t$, sedangkan Rasio Gap periode sensitivitas > 3-12 bulan tidak terdistribusi normal karena nilai signifikansi dibawah 0,05 sehingga pengujian menggunakan uji Mann-Whitney.

\section{Uji Beda}

\section{Uji † (t-test)}

Pada Tabel 4.4. dapat dilihat bahwa $F$ hitung levene test Rasio Gap periode sensitivitas $\leq 1$ bulan dan $>1-3$ bulan memiliki nilai signifikansi $>0,05$ 
Askarullah, et al/Jurnal Ekonomi Syariah Teori dan Terapan Vol. 4 No. 8 Agustus 2017: 613-629; PERBANDINGAN PEMBENTUKAN GAP SENSITIVITAS PADA BANK SYARIAH MANDIRI (BSM) DAN BANK MEGA PERIODE 2011-2015

sehingga analisis uji beda t-test harus menggunakan asumsi equal variance assumed. Dari output terlihat bahwa Rasio Gap periode sensitivitas $\leq 1$ bulan dan $>1$ 3 bulan memiliki nilai signifikansi yang kurang dari 0,05 sehingga dapat disimpulkan bahwa pembentukan gap sensitivitas antara BSM dan Bank Mega pada periode sensitivitas $\leq 1$ bulan dan $>$ 1-3 bulan berbeda secara signifikan.

Tabel 4.4.

Hasil Uji Beda T (T-Test)

\begin{tabular}{|c|c|c|c|c|c|}
\hline \multirow{2}{*}{ Var. } & & \multicolumn{2}{|c|}{ Leven's Test } & \multirow{2}{*}{ Sig. } & \multirow{2}{*}{ Ket. } \\
\hline & & $\mathrm{F}$ & Sig. & & \\
\hline \multirow{2}{*}{$\begin{array}{c}\text { Rasio } \\
\text { Gap } \\
\text { Sensitivi } \\
\text { tas } \leq 1 \\
\text { bulan }\end{array}$} & $\begin{array}{c}\text { Equal } \\
\text { variances } \\
\text { assumed }\end{array}$ & 2.580 & 147 & .000 & $\begin{array}{l}\text { Ho ditolak } \\
\text { (Terdapat } \\
\text { perbedaan) }\end{array}$ \\
\hline & $\begin{array}{c}\text { Equal } \\
\text { variance } \\
\text { not } \\
\text { assumed }\end{array}$ & & & .000 & \\
\hline \multirow{2}{*}{$\begin{array}{c}\text { Rasio } \\
\text { Gap } \\
\text { Sensitivi } \\
\text { Tas }>1- \\
3 \text { bulan }\end{array}$} & $\begin{array}{c}\text { Equal } \\
\text { variances } \\
\text { assumed }\end{array}$ & 1.377 & .274 & .027 & $\begin{array}{l}\text { Ho ditolak } \\
\text { (Terdapat } \\
\text { perbedaan) }\end{array}$ \\
\hline & $\begin{array}{c}\text { Equal } \\
\text { variance } \\
\text { not } \\
\text { assumed }\end{array}$ & & & .030 & \\
\hline
\end{tabular}

\section{Uji Mann-Whitney}

Tabel 4.5 .

Hasil Uji Mann-Whitney

Test Statistics ${ }^{a}$

\begin{tabular}{|l|r|}
\hline \multirow{2}{*}{} & RASIO GAP \\
& SENSITIVITAS \\
& $3-12$ BULAN \\
\hline Mann-Whitney U & 9.000 \\
Wilcoxon W & 24.000 \\
Z & -.731 \\
\hline Asymp. Sig. (2-tailed) & .465 \\
Exact Sig. [2*(1-tailed Sig.)] & $.548^{\mathrm{b}}$ \\
\hline
\end{tabular}

a. Grouping Variable: BANK UMUM SAMPEL

b. Not corrected for ties.

Berdasarkan hasil perhitungan uji beda dengan uji Mann-Whitney pada Tabel 4.5. diatas dapat diketahui bahwa nilai Asymp. Sig. (2-tailed) Rasio Gap periode sensitivitas > 3-12 bulan sebesar 0,465 . Nilai signifikansi ini lebih besar dari batas 0,05 sehingga dapat disimpulkan bahwa pembentukan gap sensitivitas antara BSM dengan Bank Mega pada periode sensitivitas > 3-12 bulan tidak terdapat perbedaan yang signifikan.

\section{Pembahasan}

\section{Dampak Posisi Gap}

Tabel 4.6

Perkembangan NIM BSM dan Bank Mega Periode 2011 - 2015 (Miliar Rupiah)

\begin{tabular}{|c|c|c|c|c|c|c|c|}
\hline \multirow{2}{*}{ Periode } & \multicolumn{2}{|c|}{ Posisi Gap } & \multirow{2}{*}{\begin{tabular}{c} 
Tingkat \\
\cline { 6 - 8 }
\end{tabular}} & BI Rate & $\begin{array}{c}\text { Bank } \\
\text { Mega }\end{array}$ & & \multicolumn{4}{|c|}{$\begin{array}{c}\text { Nank Syariah } \\
\text { Mandiri }\end{array}$} & \multicolumn{2}{c|}{ Bank Mega } \\
\hline 2011 & Negatif & Negatif & Naik & 7,48 & - & 5.40 & - \\
\hline 2012 & Negatif & Negatif & Turun & 7,25 & Turun & 6.45 & Naik \\
\hline 2013 & Negatif & Negatif & Naik & 7,25 & Tetap & 5.38 & Turun \\
\hline 2014 & Negatif & Negatif & Naik & 6,20 & Turun & 5.27 & Turun \\
\hline 2015 & Negatif & Negatif & Turun & 6,53 & Naik & 6.04 & Naik \\
\hline
\end{tabular}

Sumber : Hasil Penelitian, data diolah.

Berdasarkan Tabel 4.6., posisi gap yang terbentuk pada BSM dan Bank Mega secara kumulatif selama periode penelitian adalah negatif. Hal tersebut mengindi-kasikan sumber dana pihak ketiga pada BSM dan Bank Mega sebagian besar memiliki periode sensitivitas yang pendek ( $\leq 12$ bulan) sedangkan penempatan dana untuk pendanaan memiliki periode sensitivitas yang panjang (> 12 bulan).

Hasil penelitian tersebut juga sesuai dengan literatur yang dikemukakan Kopenhaver (1985) dan Supriyanto (2015) bahwa sebagian besar perbankan menggunakan liabilitas jangka pendek untuk membiayai asetnya, baik dengan jangka waktu pendek maupun panjang. Teori gap yang dikemukakan Riyadi 
(2006), dalam keadaan posisi gap negatif pengaruh perubahan tingkat suku bunga benchmark terhadap pendapatan terjadi dalam dua kondisi, pertama, pendapatan akan meningkat jika tingkat suku bunga benchmark menurun, dan kedua, pendapatan akan menurun jika tingkat suku bunga benchmark meningkat.

Teori tersebut sesuai dengan NIM yang dihasilkan oleh Bank Mega selama periode penelitian. NIM Bank Mega mengalami peningkatan disaat $\mathrm{BI}$ Rate mengalami penurunan dan sebaliknya mengalami penurunan disaat $\mathrm{BI}$ Rate menunjukkan peningkatan, namun pengaruh perubahan tingkat suku bunga benchmark kaitannya dengan pembentukan gap dirasakan berbeda oleh BSM walaupun secara umum selama periode penelitian BSM mampu menghasilkan NIM yang lebih tinggi.

Pada tahun 2012, NIM BSM justru turun dalam keadaan posisi gap negatif dan Bl Rate menunjukkan penurunan sedangkan pada tahun 2014, NIM BSM mengalami penurunan lebih tajam dibandingkan Bank Mega ditengah keadaan posisi gap negatif dan BI Rate menunjukkan peningkatan. Berdasarkan Maturity Profile BSM selama periode penelitian, struktur terbesar aset adalah pembiayaan Murabahah, sedangkan disisi liabilitas, struktur terbesar adalah Deposito Mudharabah. Karakter akad Murabahah berbeda dengan akad Mudharabah yang menggunakan pendekatan profit sharing, dimana penetapan tingkat margin dalam
Murabahah ditentukan di awal (ex-ante) dan tidak berubah hingga selesainya pembiayaan (fixed). Dengan begitu, sisi aset BSM akan sulit menyesuaikan diri terhadap perubahan pada tingkat suku bunga benchmark sedangkan di sisi liabilitas, pembagian keuntungan ditetapkan secara variable.

Penelitian yang dilakukan Rosly (1999) menemukan bahwa mayoritas pembiayaan pada Perbankan Malaysia yang didominasi pembiayaan dengan tingkat margin tetap seperti Al Bay' Bithaman 'Ajil dan Murabahah, menyebabkan penurunan pendapatan seiring dengan meningkatnya tingkat suku bunga benchmark. Dalam keadaan tingkat suku bunga benchmark menurun seperti pada tahun 2012, perbankan konvensional dalam hal ini Bank Mega lebih mampu menawarkan kredit dengan tingkat bunga yang rendah, sedangkan BSM dengan mayoritas piutang Murabahah membuat tingkat margin yang ditawarkan menjadi lebih tinggi dari tingkat bunga pasar. Akibatnya, deposan lebih memilih menggunakan kredit pada perbankan konvensional. Hal tersebut kemudian membuat BSM mengalami penurunan NIM. Dan dalam keadaan tingkat suku bunga benchmark meningkat seperti pada tahun 2014, pembiayaan Murabahah memang lebih murah daripada kredit yang ditawarkan perbankan konvensional karena tidak bisa serta merta merubah tingkat margin, namun karena struktur gap didominasi Deposito Mudharabah, mem-buat BSM 
harus meningkatkan tingkat bagi hasil agar kompetitif. Akibatnya biaya dana berupa bagi hasil yang dibagikan kepada deposan meningkat.

Dalam sistem keuangan ekonomi Islam yang sesuai dengan kaidah fikih yaitu yang tidak melanggar prinsip dasar riba al-fadhl (riba yang terjadi ketika pertukaran antarbarang sejenis dengan kadar atau takaran yang berbeda, sedangkan barang yang dipertukarkan itu termasuk dalam jenis barang ribawiAntonio, 2001:41) maka seharusnya di perbankan syariah pengelolaan pendapatan yang didasarkan atas kecocokan maturity (jatuh tempo) sesuai akadnya, akan memisahkan pengelolaan bank syariah berdasarkan aset jangka pendek (murabahah, istishna dan salam), medium term investment (ijarah, istishna), dan kemitraan jangka panjang (mudharabah, musharakah) (Greuning \& lqbal, 2008).

Dengan sistem Assets and Liability Management (ALMA) tersebut maka tingkat margin dan bagi hasil perbankan syariah tidak akan berfluktuasi karena terjadi perubahan variable pasar. Secara teori risk management dalam Supriyanto (2015:189), aset dan liabilitas dengan Maturity Profile (Analisa Jatuh Tempo) berdasarkan periode sensitivitas yang hampir sama akan menghasilkan gap yang mendekati nol atau risk netral sehingga akan kebal terhadap perubahan variable pasar seperti tingkat suku bunga. Pengelolaan berdasarkan kecocokan maturity (jatuh tempo) ini juga akan memperkecil selisih profit yang dibagikan kepada nasabah setiap bulan dengan realisasi profit pada bulan berjalan untuk deposito mudharabah yang jatuh tempo tidak pada saat pembagian profit setiap akhir bulan. Pengelolaan dengan prinsip alokasi aset yang sesuai dengan jangka waktu liabilitas akan menetralkan posisi neraca perbankan syariah terhadap risiko perubahan variable pasar (Risiko Pasar), seperti pengaruh tidak langsung suku bunga pada margin, harga komoditas dan harga mata vang.

\section{Pembahasan Uji Beda}

\section{Periode Sensitivitas $\leq 1$ Bulan}

Berdasarkan uji yang telah dilakukan, dapat dinyatakan bahwa pembentukan gap sensitivitas antara BSM dan Bank Mega pada periode sensitivitas $\leq 1$ bulan dilihat dari Rasio Gap berbeda secara signifikan. Adapun posisi gap yang dihasilkan oleh BSM dan Bank Mega adalah negatif.

Komposisi RSL periode sensitivitas $\leq$ 1 bulan pada kedua bank menunjukkan pola yang sama, yaitu sebagian besar memiliki jatuh tempo pada periode sensitivitas ini. Sedangkan disisi RSA, komposisi pada kedua bank menunjukkan jumlah yang berbeda, dimana RSA Bank Mega secara umum lebih besar daripada BSM selama tahun 2011 - 2015. Hal inilah yang menyebabkan pembentukan gap pada kedua bank kemudian menjadi berbeda signifikan.

Tabel 4.6 
Askarullah, et al/Jurnal Ekonomi Syariah Teori dan Terapan Vol. 4 No. 8 Agustus 2017: 613-629; PERBANDINGAN PEMBENTUKAN GAP SENSITIVITAS PADA BANK SYARIAH MANDIRI (BSM) DAN BANK MEGA PERIODE 2011-2015

Jumlah Penempatan di Bank Indonesia dan Bank Lain tahun 2011-2015 (Dalam Miliar Rupiah)

\begin{tabular}{|c|c|c|c|c|c|}
\hline & 2011 & 2012 & 2013 & 2014 & 2015 \\
\hline BSM & $7.133,8$ & $5.595,4$ & $9.107,1$ & $10.962,8$ & $6.512,7$ \\
\hline Bank Mega & $10.248,4$ & $8.394,8$ & $11.240,9$ & $7.803,3$ & $8.438,3$ \\
\hline
\end{tabular}

Sumber : Maturity Profile Tahun 2011-2015 BSM dan Bank Mega

Struktur pembentuk RSA yang dominan pada periode sensitivitas $\leq 1$ bulan seperti yang ditunjukkan oleh Tabel 4.6 adalah komponen penempatan pada pasar vang, baik pada Bank Indonesia maupun Bank lain.

Dari Tabel 4.6 dapat dilihat bahwa jumlah penempatan oleh Bank Mega selalu lebih besar daripada BSM selama periode penelitian kecuali pada tahun 2014. Hal tersebut mengindikasikan BSM kurang leluasa dalam mengalokasikan dananya pada instrumen-instrumen pasar vang. Alamsyah (2012:7) mengemukakan hal ini disebabkan oleh faktor bisnis model industri keuangan syariah di Indonesia, khususnya perbankan syariah, yang lebih fokus pada pemenuhan kebutuhan di sektor riil dan sangat menjaga "maqasid syariah". Hal ini berbeda dengan negara lain yang peranan produk-produk di sektor kevangan (pasar vang dan pasar modal) lebih dominan walaupun secara esensi, struktur pengembangan keuangan syariah di Indonesia akan lebih kuat dibanding dengan negara lain.

Kekurangan instrumen di pasar kevangan syariah tersebut berdampak pada manajemen gap BSM untuk periode sensitivitas $\leq 1$ bulan ini sehingga jumlah RSA yang dimiliki tidak mampu mengimbangi RSL seperti pada Bank Mega.

\section{Periode Sensitivitas $>$ 1-3 bulan}

Berdasarkan uji yang telah dilakukan, dapat dinyatakan bahwa pembentukan gap sensitivitas antara BSM dan Bank Mega pada periode sensitivitas > 1-3 bulan dilihat dari Rasio Gap berbeda secara signifikan.

Secara kumulatif posisi gap yang terbentuk pada periode sensitivitas > 1-3 bulan pada kedua bank adalah negatif, namun BSM mampu menghasilkan posisi gap positif selama tahun 2013-2015 sedangkan pada Bank Mega secara keseluruhan adalah negatif. Perbedaan posisi gap yang dihasilkan tersebut menyebabkan hasil perhitungan uji statistik untuk pembentukan gap menunjukkan perbedaan yang signifikan.

Struktur pembentuk RSL Bank Mega pada periode sensitivitas $>$ 1-3 bulan terdiri dari simpanan dari nasabah, simpanan dari bank lain dan pinjaman yang diterima. Sedangkan RSL pada BSM hanya terdiri dari Dana Syirkah Temporer (DST) yang meliputi Deposito Mudharabah dan Deposito Mudharabah dari Bank Lain. Perkembangan RSL selama 2011-2015 ditunjukkan oleh Tabel 4.7. dibawah ini :

Tabel 4.7.

Perkembangan RSL BSM dan Bank Mega Periode Sensitivitas > 1-3 Bulan

Tahun 2011 - 2015 (Miliar Rupiah)

\begin{tabular}{|l|c|c|c|c|c|}
\hline \multirow{2}{*}{ Komponen RSL } & \multicolumn{5}{|c|}{ Jumlah } \\
\cline { 2 - 6 } & $\mathbf{2 0 1 1}$ & $\mathbf{2 0 1 2}$ & $\mathbf{2 0 1 3}$ & $\mathbf{2 0 1 4}$ & $\mathbf{2 0 1 5}$ \\
\hline \multicolumn{7}{|c|}{ BSM } \\
\hline Deposito Mudharabah & $3.815,4$ & $7.574,1$ & $2.782,5$ & $4.045,0$ & $3.384,0$ \\
\hline $\begin{array}{l}\text { Deposito Mudharabah } \\
\text { dari Bank Lain }\end{array}$ & 3,2 & 55,4 & 1,9 & 2,8 & 2,0 \\
\hline \multicolumn{7}{|c|}{ Total } & $3.818,60$ & $7.629,50$ & $2.784,40$ & $4.047,80$ & $3.386,00$ \\
\hline \multicolumn{7}{|c|}{ Bana } \\
\hline Simpanan dari Nasabah & $9.201,7$ & $3.915,1$ & $9.298,0$ & $8.724,9$ & $9.944,3$ \\
\hline $\begin{array}{l}\text { Simpanan dari Bank } \\
\text { Lain }\end{array}$ & 86,4 & 29,2 & 25,5 & 93,4 & 544,4 \\
\hline Pinjaman yang Diterima & - & 192,8 & 121,7 & 92,9 & 572,1 \\
\hline \multicolumn{1}{|c|}{ Total } & $9.288,10$ & $4.137,10$ & $9.445,20$ & $8.911,20$ & $11.060,80$ \\
\hline
\end{tabular}


Askarullah, et al/Jurnal Ekonomi Syariah Teori dan Terapan Vol. 4 No. 8 Agustus 2017: 613-629; PERBANDINGAN PEMBENTUKAN GAP SENSITIVITAS PADA BANK SYARIAH MANDIRI (BSM) DAN BANK MEGA PERIODE 2011-2015

Sumber : Maturity Profile Tahun 2011-2015 BSM dan Bank Mega, diolah.

Tabel 4.7. diatas memperlihatkan bahwa jumlah RSL BSM pada periode sensitivitas > 1-3 bulan selalu lebih kecil daripada Bank Mega kecuali pada tahun 2012. Adapun struktur RSL pada kedua bank untuk periode sensitivitas $>1-3$ bulan didominasi oleh deposito.

Kecilnya volume deposito BSM untuk periode sensitivitas $>1-3$ bulan ini disebabkan perilaku menabung di perbankan syariah paling dipengaruhi oleh tingkat bagi hasil (profit distribution). Deposan (nasabah) perbankan syariah di Indonesia terbagi dalam beberapa segmentasi pasar. Karim dan Affif (2005) menyatakan bahwa di Indonesia ditemukan tiga segmentasi pasar, yaitu sharia loyalist (terdiri dari penganut agama yang patuh), floating segment (kombinasi agama dan kekuatan pasar) dan conventional loyalist. Penelitian yang dilakukan oleh Khairunnisa (2001) menemukan bahwa deposan di Indonesia mengincar profit maximization. Penelitian Mangkuto (2004) juga menegaskan bahwa faktor yang menjadi pertimbangan masyarakat menginvestasikan dananya di perbankan syariah adalah faktor return bagi hasil.

\section{Periode Sensitivitas > 3-12 Bulan}

Berdasarkan uji yang telah dilakukan, dapat dinyatakan bahwa pembentukan gap sensitivitas antara BSM dan Bank Mega pada periode sensitivitas $>3$ 12 bulan dilihat dari Rasio Gap tidak terdapat perbedaan yang signifikan.
Pembentukan gap kedua bank untuk periode sensitivitas $>3-12$ bulan menunjukkan posisi yang sama yaitu positif dengan jumlah yang tidak jauh berbeda selama tahun 2011-2015. Hal inilah yang kemudian menyebabkan hasil uji statistik dilihat dari Rasio Gap-yang merupakan persentase posisi gap terhadap total asetmenunjukkan tidak terdapat perbedaan yang signifikan.

Posisi Gap periode sensitivitas > 312 bulan pada BSM dan Bank Mega yang menunjukkan hasil tidak berbeda secara signifikan disebabkan oleh kesamaan alokasi RSA dan RSL kedua bank tersebut pada periode sensitivitas ini. Berdasarkan Maturity Profile (Analisa Jatuh Tempo) BSM dan Bank Mega, periode sensitivitas $>$ 3-12 bulan secara umum menjadi periode sensitivitas dengan jumlah RSA terbesar kedua setelah periode sensitivitas $\leq 1$ bulan dan disisi lain memiliki jumlah RSL terkecil dibandingkan dua periode sensitivitas lainnya $(\leq 1$ bulan dan $>1-3$ bulan).

Jumlah RSA periode sensitivitas $>3-$ 12 bulan yang lebih besar daripada periode sensitivitas > 1-3 bulan tentu dipengaruhi oleh jangka waktu yang lebih lama, namun jumlah RSL yang lebih kecil dibandingkan dua periode sensitivitas sebelumnya menjadi indikator terbatasnya produk penghimpunan dana pada periode sensitivitas $>3-12$ bulan baik di BSM maupun Bank Mega. Walaupun secara prinsip dasar berbeda, produk penghimpunan dana di BSM sebagai Bank Syariah dan Bank Mega sebagai 
Bank Konvensional terdiri dari tiga struktur utama, yaitu giro, tabungan, dan deposito. Deposito memiliki karakter yang berbeda dibandingkan dengan giro dan tabungan karena terdapat tenggang waktu penyimpanan. Adanya tenggang waktu tersebut membuat tujuan utama dari penggunaan produk deposito adalah investasi daripada motif berjaga-jaga. Tenggang waktu tersebut juga menyebabkan struktur pembentuk RSL pada periode sensitivitas yang lebih panjang akhirnya didominasi oleh deposito.

Secara teknis pada perbankan konvensional, ketergantungan sumber dana pihak ketiga berupa deposito untuk memenuhi kebutuhan likuiditas akan membuat bank cenderung harus membayar bunga yang lebih tinggi dibandingkan giro dan tabungan dan juga akan mengalami variasi yang lebih besar dalam biaya dana-dana (Arifin, 2009:147). Perbankan konvensional cenderung menghindari hal tersebut dengan lebih memilih menggunakan sumber dana dengan jangka pendek untuk membiayai kredit jangka panjang agar meminimalisir pengaruh negatif volatilitas tingkat suku bunga terhadap profitabilitasnya. BSM sebagai bank syariah seharusnya tidak perlu mengkhawatirkan biaya-biaya dana tersebut karena deposito dengan akad mudharabah menggunakan pendekatan profit sharing (seperti penjelasan pada subbab 4.4.1.2) sehingga biaya dana yang timbul disesuaikan dengan kinerja bukan bunga yang dijanjikan. Namun, seperti juga pada penjelasan sebelumnya, karakter deposan perbankan syariah serta tingkat bagi hasil menjadi daya tawar kritis bagi BSM. Sosialisasi serta peningkatan kinerja menjadi hal yang perlu dilakukan oleh BSM agar kualitas sumber dana dari pihak ketiga serta pengaturan gap untuk periode sensitivitas yang lebih panjang menjadi lebih baik daripada perbankan konvensional.

\section{SIMPULAN}

Simpulan dari hasil analisis gap sensitivitas pada Bank Syariah Mandiri (BSM) dan Bank Mega pada periode 2011-2015 adalah:

1. Untuk BSM, posisi gap yang terbentuk pada periode sensitivitas $\leq 1$ bulan adalah negatif gap, periode sensitivitas $>1-3$ bulan adalah negatif gap, dan pada periode sensitivitas $>3$ 12 bulan adalah positif gap.

2. Untuk Bank Mega, posisi gap yang terbentuk pada periode sensitivitas $\leq 1$ bulan adalah negatif gap, periode sensitivitas $>1-3$ bulan adalah negatif gap, dan pada periode sensitivitas $>3$ 12 bulan adalah positif gap.

3. Walaupun selama periode penelitian BSM mampu menghasilkan NIM yang lebih tinggi, namun eksposur risiko perubahan tingkat suku bunga benchmark pada BSM lebih tinggi daripada Bank Mega dikarenakan penggunan dominan pembiayaan Murabahah (fixed rate) pada sisi aset dengan jangka waktu panjang sedangkan sisi 
liabilitas didominasi Deposito

Mudharabah (variable rate) dengan

jangka waktu pendek.

Simpulan dari uji beda pembentukan gap pada BSM dan Bank Mega Periode 2011-2015 adalah:

1. Berdasarkan uji beda $(a=0,05)$ pembentukan gap pada periode 2011-2015 untuk periode sensitivitas $\leq 1$ bulan dan > 1-3 bulan terdapat perbedaan signifikan, sedangkan pada periode sensitivitas $>3-12$ bulan tidak terdapat perbedaan siginifikan.

Saran yang direkomendasikan adalah:

1. Bagi Bank Syariah Mandiri (BSM) mengupayakan agar melakukan penyesuian jatuh tempo aset dan liabilitasnya.

2. Bagi BSM mengupayakan untuk mengurangi ketergantungan terhadap komponen RSA seperti Pembiayaan Murabahah dan meningkatkan volume komponen yang berbasis profit sharing seperti Pembiayaan Mudharabah dan Musyarakah agar mengurangi risiko akibat fluktuatifnya perubahan tingkat suku bunga benchmark.

3. Bagi penelitian selanjutnya diharapkan melengkapi analisis gap dengan menyertakan simulasi kenaikan atau penurunan tingkat suku bunga benchmark agar objek yang diteliti memperoleh strategi dalam mengatasi perubahan suku bunga. Penggunanaan duration gap dirasakan perlu sehingga peneliti selanjutnya dapat mengetahui secara tepat return dan cost dari masing-masing asset dan liabilitasnya.

\section{DAFTAR PUSTAKA}

Alamsyah, D. H., 2012. Perkembangan dan Prospek Perbankan Syariah Indonesia: Tantangan Dalam Menyongsong MEA 2015. Makalah disampaikan dalam Ceramah IImiah Ikatan Ahli Ekonomi Islam (IAEI), Milad ke-8 IAEI, Hal. 1-8.

Ali, M., 2004. Asset-Liability Management: Menyiasati Risiko Pasar dan Risiko Operasional dalam Perbankan. Jakarta: Elex Media Komputindo.

Alsa, Y. I. 2004. Pengaruh Kualitas Asset dan Liabilitas Terhadap Kinerja Perbankan Syariah. Tesis Tidak Diterbitkan. Semarang: Universitas Diponegoro.

Antonio, M. S. 2001. Bank Syariah Dari Teori Ke Praktik. Jakarta: Gema Insani Press.

Arifin, Z., 2009. Dasar-Dasar Manajemen Bank Syariah. 7 ed. Jakarta: Azkia Publisher

Chapra, M. U., \& Ahmed, H. 2002. Corporate Governance in Islamic Financial Institutions. Riyadh: Islamic Development Bank.

Greuning, H. V. \& lqbal, Z., 2008. Analysis for Islamic Bank. Washington: World Bank.

Hanafi, M., 2009. Manajemen Risiko. Edisi Kedua. Yogyakarta: UPP STIM YKPN.

Karim, A. A. 2014. Bank Islam: Analisis Fiqih dan Keuangan. Edisi Kelima. Jakarta: PT RajaGrafindo Persada. 
Karim, A. A. \& Affif, A. Z., 2005. Islamic Banking Consumer Behaviour in Indonesia: A Qualitative Approach. International Journal Islamic Finance, 5(1). pp. 1-18.

Khairunnisa, D., 2001. Preferensi Masyarakat Terhadap Bank Syariah (Studi Kasus Bank Muamalat Indonesia dan BNI Syariah). Yogyakarta, P3ElFEUII.

Koppenhaver, G. D., 1985. Bank Funding Risks, Risk Aversions, and The Choice of Futures Hedging Instrument. The Journal of Finance, XL(1), pp. 241-255.

Kountur, R. 2006. Manajemen Risiko. Jakarta: Abdi Tandur.

Loristiana, D. W. 2009. Analisis Sensitivitas Gap Suku Bunga dan Nilai Tukar Bank Rakyat Indonesia Periode 2007-2008. Skripsi Tidak Diterbitkan. Bogor: Institut Pertanian Bogor.

Mangkuto, I., 2004. Pengaruh Tingkat Suku Bunga Deposito Bank Konvensional dan Tingkat Pendapatan Deposito Mudharabah Terhadap Pertumbuhan Deposito di Bank Muamalat. Tesis tidak dipublikasikan. Jakarta: Universitas Indonesia.

Muhamad. 2015. Manajemen Dana Bank Syariah. Jakarta: Rajawali Pers.

Muslich, M. 2007. Manajemen Risiko Operasional: Teori dan Praktik. Jakarta: Sinar Grafika Offset.

Riyadi, S. 2006. Banking Assets and Liability Managements. Jakarta: Lembaga Penerbit Fakultas Ekonomi Universitas Indonesia.
Rosly, S. A., 1999. Al-Bay' Bithaman "Ajil Financing: Impacts on Islamic Banking Performance. Thunderbird International Business Review, 41 (4/5), pp. 461-480.

Supriyanto, T., 2015. Konsep Rate of Profit dan Stabilitas Ekonomi Perbankan Syariah. Jurnal Etikonomi, 14(2), Hal. 175-204. 